\title{
ARTICLE
}

\section{A novel peptide specifically binding to VEGF receptor suppresses angiogenesis in vitro and in vivo}

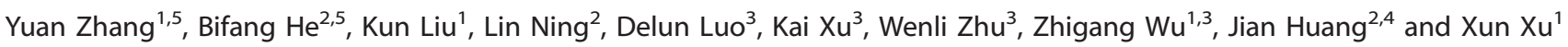

Vascular endothelial growth factor (VEGF), one of the most important angiogenic factors, plays an essential role in both physiological and pathological angiogenesis through binding to VEGF receptors (VEGFRs). Here we report a novel peptide designated HRHTKQRHTALH (peptide HRH), which was isolated from the Ph.D. -12 phage display library using VEGFR-Fc fusion protein as the bait. This peptide was found to dose-dependently inhibit the proliferation of human umbilical vein endothelial cells stimulated by VEGF. The anti-angiogenesis effect of the HRH peptide was further confirmed in vivo using the chick chorioallantoic membrane assay, which was also dose-dependent. Besides, peptide HRH was proved to inhibit corneal neovascularization in an alkali-burnt rat corneal model and a suture-induced rat corneal model. Taken together, these findings suggest that the HRH peptide can inhibit angiogenesis both in vitro and in vivo. Consequently, the HRHTKQRHTALH peptide might be a promising lead peptide for the development of potential angiogenic inhibitors.

Signal Transduction and Targeted Therapy (2017) 2, e17010; doi:10.1038/sigtrans.2017.10; published online 12 May 2017

\section{INTRODUCTION}

The deregulated and persistent angiogenesis is a critical hallmark of neovascular or exudative age-related macular degeneration (AMD). ${ }^{1}$ Overwhelming evidence has reported that abnormal angiogenesis is involved in many other pathological disorders including cancer, which are termed as angiogenesis-dependent diseases. ${ }^{2}$ Anti-angiogenesis treatment has become the standardof-care therapy for angiogenesis-induced complications such as neovascular AMD and retinopathy of prematurity. ${ }^{3,4}$

Vascular endothelial growth factor (VEGF) is a pivotal angiogenic factor, which signals through its receptors on the cell surface to manipulate multiple facets of angiogenesis. ${ }^{5}$ The upregulated expression of VEGF is often present in patients with angiogenesisrelated pathological disorders. Hence, the inhibition of VEGF has been already applied widely in the treatment of intraocular neovascular disorders. In fact, a large number of anti-VEGF agents have been developed. ${ }^{6-9}$ Many clinical trials have shown that the injection of anti-VEGF drugs has significant curative effects on ocular diseases driven by abundant angiogenesis. ${ }^{10-15}$ However, these existing therapeutic drugs are not effective to all patients, and many show decreased responsiveness and drug resistance in the course of therapy. ${ }^{16}$ Another problem is the consecutive intravitreal injections of drugs are costly and risky. Therefore, more new drugs that respond to more patients and, particularly, agents that would produce curative efficacy when administered by safer and simpler ways are needed urgently in treating AMD and other angiogenesis-dependent diseases.

Currently, most angiogenic inhibitors in clinical use are proteins, and a few are small molecules. ${ }^{6}$ Small-molecule therapeutics may sustain reduced target selectivity because of their fairly small size, whereas protein drugs are inclined to have high target specificity owning to more interactions between them, however this comes at the expense of poor membrane permeability, metabolic instability and low bioavailability. ${ }^{17}$ Fortunately, peptide agents have the advantages of both small molecules (low cost, oral bioavailability, membrane permeability, metabolic stability and conformational restriction) and proteins (target specificity and high potency). Also, to optimize efficacy and enhance metabolic stability, chemical modifications can be integrated into peptide synthesis, which can improve druggability. ${ }^{18}$ Therefore, compared with therapeutic proteins, synthetic peptides have several advantages as drug candidates. Phage display technology was first described by George P Smith in $1985,{ }^{19}$ which has been extensively used for the identification of peptide ligands with high specificity for a given target. ${ }^{20-24}$ This approach has a few advantages over conventional random screening methods in drug discovery: less time-consuming, cost-effective and easy to operate. Giordano et al. $^{25}$ adopted a phage-displayed peptide libraryscreening approach and identified the peptide CPQPRPLC specifically binding to VEGF receptor-1 (VEGFR-1) and neuropilin-1. Very recently, the derived peptidomimetic [D(CLPRC)], also known as Vasotide, has been reported to reduce retinal angiogenesis through either eye drops or intraperitoneal injection into three animal models. ${ }^{26}$

To obtain more novel anti-angiogenesis peptide ligands, in the current study, we screened the Ph.D. -12 phage display library against VEGFR-Fc fusion protein. And then an identified peptide with the sequence HRHTKQRHTALH was synthesized, and its antiangiogenesis abilities were evaluated and confirmed in vitro and in vivo. This peptide holds great promise as an angiogenic inhibitor for the treatment of ophthalmic diseases caused by excessive angiogenesis.

\footnotetext{
${ }^{1}$ Department of Ophthalmology, Shanghai General Hospital, Shanghai Jiaotong University School of Medicine, Shanghai, China; ${ }^{2}$ Key Laboratory for Neurolnformation of Ministry of Education, School of Life Science and Technology, University of Electronic Science and Technology of China, Chengdu, China; ${ }^{3}$ Chengdu Nuoen Biotechnologies, LTD, Chengdu, China and ${ }^{4}$ Center for Informational Biology, University of Electronic Science and Technology of China, Chengdu, China.

Correspondence: J Huang (hj@uestc.edu.cn) or X Xu (tmsmile@sina.com.cn)

${ }^{5}$ These authors contributed equally to this work.

Received 9 October 2016; revised 21 February 2017; accepted 21 February 2017
} 


\section{MATERIALS AND METHODS}

\section{Phage display library and other reagents}

A 12-mer phage display library (Ph.D. -12 phage display library) was purchased from New England Biolabs (Beverly, MA, USA), which was based on a combinatorial library of random dodecapeptides fused to a minor coat protein (pllI) of M13 phage. The VEGFR-Fc fusion protein was constructed by fusing the second Ig domain of VEGFR-1 with the third Ig domain of VEGF receptor-2 (VEGFR-2) to the constant region (Fc) of human $\operatorname{lgG} 1,{ }^{27}$ and expressed in Chinese hamster ovary cells in Shanghai General Hospital (Shanghai, China). Escherichia coli K12 ER2738 for amplification of phage and wild-type M13 phage clone were also purchased from New England Biolabs.

\section{Cell culture}

Human umbilical vein endothelial cells (HUVECs) were obtained from BioWhittaker Inc. (Walkersville, MD, USA). The cells were cultured in the endothelial cell medium containing endothelial cell growth supplement (ScienCell, San Diego, CA, USA). The cells were used for the experiments at their second growth passage.

\section{Screening phage display library with VEGFR-Fc fusion protein}

The procedure for positive screening the phage display library was mainly according to instructions of the manufacturer (New England Biolabs). Briefly, the plate was coated with $50 \mu \mathrm{g}$ VEGFR-Fc fusion protein overnight at $4{ }^{\circ} \mathrm{C}$ with gentle agitation in a humidified container before blocking with phosphate buffer containing $1 \%$ bovine serum albumin for $1 \mathrm{~h}$ at $37^{\circ} \mathrm{C}$. A phage display library containing $1 \times 10^{12}$ plague-forming unit (p.f.u.) phages was added to the coated plate and incubated at room temperature. After $1 \mathrm{~h}$, the supernatant was removed. The plates were slapped face-down onto a clean paper towel and washed 16 times with TBST $(0.1 \%$ Tween-20). The bound phages were eluted with a low $\mathrm{pH}$ buffer (2.2 M glycine, pH 2.2) and amplified in E. coli K12 ER2738 for two subsequent rounds of selection on VEGFR-Fc fusion protein. In the second and third affinity selections, the plates were washed with TBST $(0.25 \%$ Tween-20) and TBST (0.5\% Tween-20). After three positive panning rounds, the positively selected phages were amplified for the next negative selection. In the first round of negative panning, $1.5 \mu \mathrm{g}$ of human $\mathrm{lgG}$ diluted in TBST $(200 \mu \mathrm{l})$ was immobilized in protein A agarose resin. Subsequently, $1 \times 10^{10}$ p.f.u. phages were mixed with the diluted IgG solution and incubated at room temperature for $20 \mathrm{~min}$. Following incubation, the phages were transferred to the tube containing protein A agarose and further allowed to bind at room temperature for $15 \mathrm{~min}$. Then, the tube was centrifuged at low speed and the supernatant was recovered. The above process was repeated for two additional rounds. The supernatant was titrated and the individual plaques were picked for DNA isolation and sequencing. Phages from selected clones were sequenced using an $\mathrm{ABI}$ machine. The above biopanning experiment was performed by Rx Biosciences, Ltd (Gaithersburg, MD, USA).

\section{Enzyme-linked immunosorbent assay for phage-binding activity} A 96-well plate was coated with $100 \mu$ l VEGFR-Fc fusion protein $\left(10 \mu \mathrm{g} \mathrm{ml}^{-1}\right)$ for each well at $4{ }^{\circ} \mathrm{C}$ overnight, then blocked with phosphate buffer containing $1 \%$ bovine serum albumin for $2 \mathrm{~h}$ at $37^{\circ} \mathrm{C}$. Phages were added to the wells and incubated at room temperature for $30 \mathrm{~min}$. The amount of bound phages was detected with a horseradish peroxidaseconjugated anti-M13 antibody. After the addition of the substrate, the optical density (OD) of each well was measured at $405 \mathrm{~nm}$ using a Microplate Reader (Molecular devices, LLC, Sunnyvale, CA, USA). Wild-type M13 phage clone was served as a negative control. The enzyme-linked immunosorbent assay assay was conducted by Rx Biosciences, Ltd.

Peptide synthesis and identification

Peptides were synthesized on a peptide synthesizer CS336X (CSBio Company Inc., Menlo Park, CA, USA) following the standard Fmoc strategy by Chengdu Nuoen Biotechnologies, Ltd (Chengdu, China). The fluorescein residue was introduced into the peptide by standard coupling of $\mathrm{N}$-terminal-deprotected peptide with fluorescein-5-carboxylic acid. Peptide amides were cleaved from the resin with trifluoroacetic acid: triisopropylsilane: water (94: 4: 2, v/v/v) and were recovered by precipitation with ice-cold diethyl ether. Crude products were purified by high-performance liquid chromatography on a C18 column using a gradient of $20-80 \%$ acetonitrile/water $(0.1 \%$ formic acid). The sequence of peptides was verified by electrospray mass spectrometry (Finnigan lontrap Mass Analyzer, Thermo, Waltham, MA, USA).

\section{HUVEC proliferation assay}

To evaluate the inhibition rate of endothelial proliferation stimulated by VEGF, HUVECs were placed into 96-well plates at 104 cells per well and incubated for $24 \mathrm{~h}$ at $37{ }^{\circ} \mathrm{C}$ in $5 \% \mathrm{CO}_{2}(100 \mu \mathrm{l}$ per well). The synthesized peptide diluted with endothelial cell growth supplement-endothelial cell medium (at varied concentrations from 0.95 to $3.85 \mu \mu_{\mu l}^{-1}$ ) and equal volume of VEGF solution ( $40 \mathrm{ng} \mathrm{ml}^{-1}$ ) were mixed and incubated for $3 \mathrm{~h}$ at $37^{\circ} \mathrm{C}$. The peptide and VEGF mixture solution were added to each well of the plates $\left(100 \mu \mathrm{l}\right.$ per well) and incubated for $96 \mathrm{~h}$ at $37^{\circ} \mathrm{C}$, and then they were treated with CCK- 8 solution $(25 \mu \mathrm{l}$ per well). The absorbance was determined at $450 \mathrm{~nm}$ using a Microplate Reader (Molecular devices, LLC). The endothelial cell growth supplement-endothelial cell medium medium was used as a blank control. The VEGFR-Fc fusion protein was used as a positive control. The VEGF was used as a negative control. The cell growth rate was defined as OD sample/OD negative $\times 100$. This experiment was performed in triplicate by Chengdu Nuoen Biotechnologies, Ltd.

In vivo study of angiogenesis using the chick chorioallantoic membrane assay

To determine anti-angiogenic activity in vivo, a chick chorioallantoic membrane (CAM) assay was performed by Shanghai General Hospital (Shanghai, China) as previously described. ${ }^{28,29}$ Two-day-old fertilized eggs (Shanghai Poultry Breeding Co. Ltd., Shanghai, China) were incubated at $37{ }^{\circ} \mathrm{C}$ and $60-70 \%$ relative humidity. After incubation for 5 days, a $1-2 \mathrm{~cm}^{2}$ window was opened and one sterilized silica gel O-type ring $(0.5 \mathrm{~cm}$ inner diameter) was placed onto the CAM of every individual embryo, and phosphate buffer solution (PBS) or peptides $\left(10,25\right.$ or $50 \mu \mathrm{g} \mu \mathrm{l}^{-1}$ ) were added inside it. The eggs were incubated for another $48 \mathrm{~h}$. The upper eggshell was removed and the area of capillary blood vessels was calculated. Capillaries were photographed under a stereomicroscope (Olympus, SZX16, Tokyo, Japan). The capillary area was calculated with Image-Pro Plus version 6.0.0.260 (Media Cybernetics, Inc., Rockville, MD, USA). The experiment was repeated three times.

\section{Animals}

Sprague-Dawley male rats were purchased from Laboratorial Animal Center of Shanghai General Hospital. All animal experiments conformed to the Association for Research in Vision and Ophthalmology Statement for the Use of Animals in Ophthalmic and Vision Research. All of the experimental protocols were approved by the Animal Investigation Committee of Shanghai General Hospital, Shanghai Jiaotong University School of Medicine. All eyes of the rats were examined before experiments to exclude any pre-existing corneal diseases. One cornea of each rat was treated as an experimental eye. All the animals were anesthetized with an intraperitoneal injection of $30 \mathrm{mg} \mathrm{kg}^{-1}$ pentobarbital and received topical anesthetization with oxybuprocaine.

The experimental rats were randomly separated into three groups (eight for each group): (1) negative control group: PBS, (2) HRH peptide group: $10 \mu \mathrm{ul}^{-1}$, (3) nonspecific peptide group: $10 \mu \mathrm{g} \mathrm{\mu l} \mathrm{l}^{-1}$, treated with eye drops (10 $\mu \mathrm{l}$ per eye drop, four times per day). Corneal neovascularization (NV) was observed and photographed with a stereomicroscope (Olympus, SZX7) on days $3,5,7,10$ and 14 after operation. The experiments were performed in triplicate. All animal experiments were performed by Shanghai General Hospital (Shanghai, China).

\section{Corneal NV induced by alkali burn}

One cornea of each Sprague-Dawley male rat in experimental groups was alkali burned. The rats were anesthetized as mentioned previously. A round filter paper of 4.0-mm diameter was soaked in $1 \mathrm{~N} \mathrm{NaOH}$ for $20 \mathrm{~s}$ and applied on the central cornea for $40 \mathrm{~s}$. After the removal of the filter paper from the cornea, the eye was rinsed with $10 \mathrm{ml}$ of sterilized saline and ofloxacin ointment was instilled. Three different eye drops were topically applied to the injured corneas for 2 weeks, including PBS, peptide $\mathrm{HRH}$ and YIT.

The corneal NV was examined and photographed on the days 3, 5, 7, 10 and 14 after alkali burn. The area of corneal NV was calculated by the following formula: area $\left.\left(\mathrm{mm}^{2}\right)=C / 12 \times 3.1416 \times\left[R^{2}-(R-L)^{2}\right]\right]^{30,31}$ The cornea image was divided into 12 clock hours. $C$ is the clock hours of 
$\mathrm{NV} ; R$ is the radius of the cornea; and $L$ is the maximal vessel length. Both $R$ and $L$ of each cornea were measured five times in vivo, and the area of corneal NV was calculated accordingly.

Rat corneal model of NV induced by intrastromal suture Suture-induced cornea NV model was performed according to a previous report with some modifications. ${ }^{32,33}$ Briefly, 10-0 nylon was sutured into the stroma of the temporal half of the cornea in a radial direction. The stitch length was $1 \mathrm{~mm}$, and outside stitching was $1 \mathrm{~mm}$ from the corneal limbus. Afterwards, treatment with eye drops continued for 2 week. The area of corneal NV was calculated by the following formula: area $\left(\mathrm{mm}^{2}\right)=0.4 \times 3.1416 \times\left[R^{2}-(R-L)^{2}\right] . R$ is the radius of the cornea and $L$ is the maximal vessel length. Both $R$ and $L$ of each cornea were measured five times in vivo.

Epitope mapping based on phage display

Peptides displayed on the identified phages were first scanned by the tools in the SAROTUP suite to exclude any possible target-unrelated peptides. ${ }^{34-39}$ The remaining peptides were then mapped back to the surface of VEGF and placenta growth factor (PIGF) based on its crystal structure (PDB: 1FLT, 2XAC, $3 \mathrm{~V} 2 \mathrm{~A}, 2 \mathrm{X} 1 \mathrm{~W}$ and 1RV6) using the EpiSearch program by default parameters. ${ }^{40}$ The mapping result with the highest score was united to make the epitope on VEGF and PIGF recognized by VEGFRs.

Data analysis and statistics

Statistical analyses were performed by SPSS for Windows version 19.0 (SPSS Inc., Chicago, IL, USA). The data were analyzed using Student's $t$-test and one-way analysis of variance. A $P$-value $<0.05$ was considered statistically significant.

Table 1. Phage-displayed peptide sequences selected by VEGFR-FC fusion protein

\begin{tabular}{lllc}
\hline Peptide & Sequence & Phage clone & Occurrence \\
\hline HRH & HRHTKQRHTALH & B12, C12, E5, E12, G8, H12 & $6 / 33$ \\
YIT & YITPYAHLRGGN & B7, C9, D7, D12 & $4 / 33$ \\
SVS & SVSVGMKPSPRP & B1, B11, D5, G12, H3 & $5 / 33$ \\
FHE & FHESWPSXAGGR & B4, C6, F9 & $3 / 33$ \\
TMG & TMGFTAPRFPHY & E1, H4, H5 & $3 / 33$ \\
TSD & TSDIKSRSPHHR & A5, D6 & $2 / 33$ \\
QTG & QTGHWNAEWHTR & A6, H7 & $2 / 33$ \\
ATK & ATKIDSLRSLHN & A10, F2 & $2 / 33$ \\
YYP & YYPASSTIQSRP & C4, F1 & $2 / 33$ \\
HWG & HWGNHSKSHPQR & D2, E11 & $2 / 33$ \\
SHP & SHPWNAQRELSV & E2, G4 & $2 / 33$ \\
\hline
\end{tabular}

\section{RESULTS}

Affinity selection of phages binding with VEGFR-Fc fusion protein and sequence analysis

We screened Ph.D. -12 phage display library of peptides binding with VEGFR-Fc fusion protein. After the last round of panning, 95 clones were randomly picked out and the peptide sequences were identified. Among the identified sequences, there were 11 peptides appearing at least twice and therefore they were considered as consensus sequences (Table 1). In addition, the binding activity of selected phage clones was estimated by enzyme-linked immunosorbent assay. Wild-type M13 phage with no inserted peptide was used as a negative control. The results revealed that selected clones displaying HRHTKQRHTALH (peptide HRH), YITPYAHLRGGN (peptide YIT) and SVSVGMKPSPRP (peptide SVS) had greater reactivity for VEGFR-Fc fusion protein compared with other phage clones (Figure 1). These three sequences were selected for further bioinformatic analysis. To exclude any possible target-unrelated peptides (TUPs) from biopanning results, all peptides were scanned using SAROTUP. ${ }^{34-37}$ The TUPScan tool in SAROTUP suggested that the SVS peptide, appearing in the output of many other phage display experiments, ${ }^{41}$ was a binder to immunoglobulin Fc region or unrelated antibodies. ${ }^{42}$ In addition, this peptide was reported to be very likely a propagation-related TUP. ${ }^{43}$ Accordingly, the peptide was excluded from further studies. The MimoSearch tool in the SAROTUP suite indicated that the YIT peptide was selected by three completely different targets. Thus, this peptide is unlikely to be a specific binder. The left $\mathrm{HRH}$

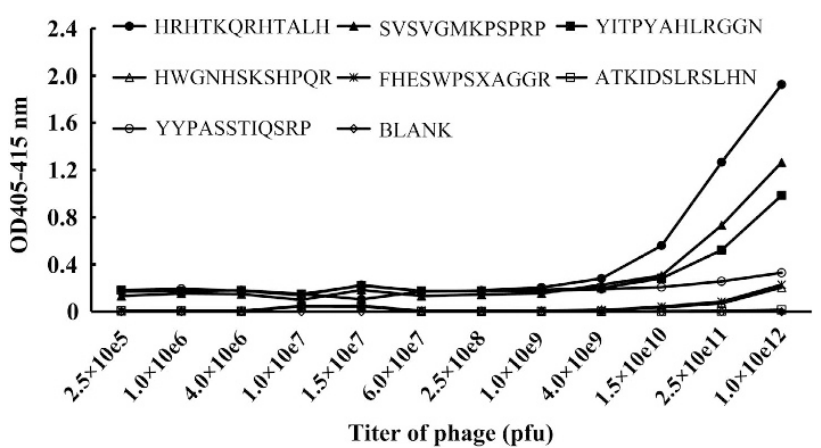

Figure 1. Binding ability of phage clones to VEGFR-Fc fusion protein. The bound phages were detected by phage enzyme-linked immunosorbent assay. The VEGFR-Fc fusion protein was incubated with phages at various titers ranging from $2.5 \times 10^{5}$ to $1 \times 10^{12}$ p.f.u. at room temperature for $30 \mathrm{~min}$. The OD value at $405-415 \mathrm{~nm}$ was measured. Wild-type M13 phage was used as a negative control (data not shown).

Table 2. Comparing epitope mapping result of HRH peptide with genuine VEGFR-binding site on ligand

\begin{tabular}{|c|c|c|c|c|}
\hline Receptor & Ligand & Complex & HRH peptide mapping results & $P D B$ sum interface \\
\hline VEGFR-1 & VEGF-B & $2 X A C$ & $\begin{array}{l}\text { T22, T25, L35, T36, L39, T42, A44, K45, } \\
\text { Q46, L47, Q79, L81, R84, Q89, L90 }\end{array}$ & $\begin{array}{l}\text { S16, W17, Y21, T22, T25, Q27, V48, P62, D63, L66, Q79, L81, S88, Q89, L90, } \\
\text { C103, P105 }\end{array}$ \\
\hline VEGFR-1 & PIGF & 1RV6 & $\begin{array}{l}\text { R35, A36, L37, R39, L63, R64, T66, T81, } \\
\text { A82, Q106, H107, R109 }\end{array}$ & $\begin{array}{l}\text { F25, Q26, W29, G30, Y33, M54, S56, G70, D71, L74, N73, Q87, L89, 191, P97, Y99, } \\
\text { C112, R113, P114 }\end{array}$ \\
\hline VEGFR-2 & VEGF-C & $2 \times 1 W$ & $\begin{array}{l}\text { R127, K128, Q130, R134, A137, R161, } \\
\text { L171, Q172, T176, H206, R210 }\end{array}$ & $\begin{array}{l}\text { T116, L119, D123, W126, R127, Q130, K142, T148, N149, F151, K153, N167, } \\
\text { S168, E169, G170, F186, I188, V190, P191, L192, G195, P196, R210, K214, L215 }\end{array}$ \\
\hline
\end{tabular}


peptide was then mapped back to the surface of VEGF and PIGF using the EpiSearch program by default parameters. ${ }^{40}$ The solutions with the highest scores were chosen, and their results were united to make the epitope on PIGF and VEGF recognized by VEGFR-1 and VEGFR-2. As shown in Table 2, we found that three to six residues in the epitope mapping results also appeared in the interfaces of VEGF-A/VEGFR-1, VEGF-B/VEGFR-1 and VEGF-C/ VEGFR-2 complexes, respectively (see the residues in bold), whereas no residues overlapped with those of PIGF/VEGFR-1 and VEGF-A/VEGFR-2 complexes. In the following experiments, the $\mathrm{HRH}$ peptide was synthesized, whereas the YIT peptide was also synthesized and used as a peptide control.

\section{Peptide HRH inhibits the proliferation of HUVEC}

The HUVEC exerts major influences on the sprout and growth of blood vessel and is commonly used to assess anti-angiogenesis activity in vitro. The inhibitory ability of peptide $\mathrm{HRH}$ on endothelial proliferation stimulated by VEGF was investigated by HUVEC. Results of the proliferation assay revealed that HUVECs treated with the HRH peptide and VEGFR-Fc fusion protein have a lower cell growth rate than those treated with only VEGF (Figure 2), which demonstrated that peptide $\mathrm{HRH}$ efficiently suppressed proliferation of HUVEC under VEGF stimulation. As shown in Figure 2, peptide $\mathrm{HRH}$ affected endothelial cell proliferation in a dose-dependent manner, and HUVECs handled with peptide $\mathrm{HRH}$ grew slower than those treated with the control peptide YIT at each concentration.

Peptide HRH suppresses angiogenesis in the CAM

To examine the in vivo anti-angiogenic activity, the CAM assay was carried out to determine the influence of peptide $\mathrm{HRH}$ on angiogenesis. Blood vessel growth rate is reflected by the increased vessel area after $48 \mathrm{~h}$ compared with original area. As shown in Figure 3, CAMs treated with the HRH peptide at the concentration of $10-50 \mu \mathrm{gl}^{-1}$ demonstrate obvious avascular area and the decrease in the area of capillaries in the treated area (Figures $3 \mathrm{~d}-1-\mathrm{d}-3$ ) in contrast to CAMs treated with PBS (Figure 3a). The area of newly-formed blood vessels was significantly decreased in a dose-dependent manner over the range from 10 to $50 \mathrm{\mu g} \mathrm{\mu l}^{-1}$ without inflammation (Figures 3d-1d3 and e). With the increase of the concentration, the difference between the inhibition of angiogenesis of peptide $\mathrm{HRH}$ and peptide YIT is much more significant (Figures 3c-1-c-3). When the concentration of the $\mathrm{HRH}$ peptide reached $50 \mathrm{\mu g} \mathrm{\mu l}^{-1}$, its inhibition capabilities on blood vessel growth can rival those of

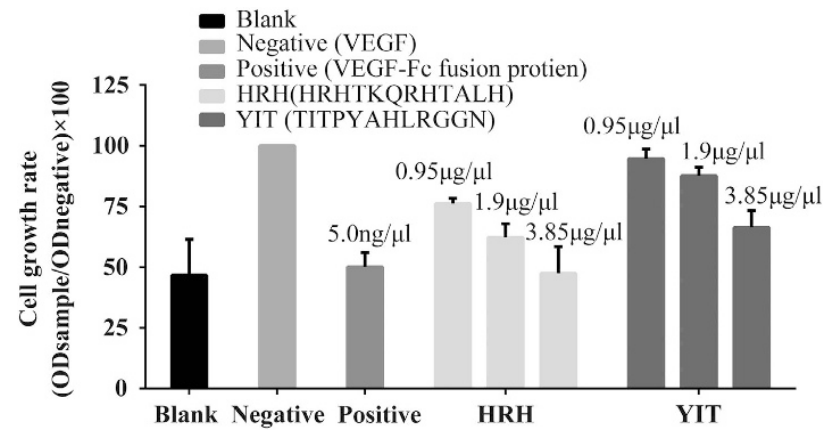

Figure 2. Inhibition rate of peptide $\mathrm{HRH}$ at various concentrations. The endothelial cell growth supplement-endothelial cell medium medium was used as a blank control. The VEGF was used a negative control. The VEGFR-Fc fusion protein was used as a positive control. The YIT peptide was used as a nonspecific peptide control. The absorbance was determined at $450 \mathrm{~nm}$. The cell growth rate was defined as OD sample/OD negative $\times 100$. the VEGFR-Fc fusion protein. These data suggest that the HRH peptide can efficiently suppress angiogenesis in chicken embryos.

Peptide HRH inhibits corneal NV in alkali-burnt rat corneal model The results of CAM assays encouraged us to determine whether peptide HRH may also affect corneal NV. Alkali-burned cornea induced obvious neovasculature, and the blood vessels in the PBS group almost covered the whole corneal stroma (Figure 4a). Most part of corneal stroma did not have blood vessels in the $\mathrm{HRH}$ group (Figure 4c) compared to the PBS group (Figure 4a) and the YIT group (Figure 4b). From days 3 to 14, the growth of the vessel in $\mathrm{HRH}$ group slowed down and the NV area increased slowly (Figure 4d). Compared to the PBS group and the YIT group, the area of corneal NV, which was treated with peptide $\mathrm{HRH}$, was significantly reduced (*** $P<0.001$, Figure $4 \mathrm{e})$.

Peptide HRH depresses corneal NV in suture-induced rat corneal model

Further investigation was performed to test the effect of peptide $\mathrm{HRH}$ on suture-induced corneal NV through observing its inhibitory effect on the growth of blood vessels. Compared with those treated with PBS and peptide YIT, corneal NV was significantly inhibited by topical administration of peptide $\mathrm{HRH}$ $(P<0.001$; Figure 5$)$. In comparison to controls, the vessel invasion area was significantly reduced.

\section{DISCUSSION}

In this study, we utilized a subtractive biopanning strategy to isolate VEGFR-binding peptides from a phage-displayed 12-mer peptide library. One peptide with the sequence HRHTKQRHTALH was identified and characterized. The HUVEC proliferation experiment demonstrated that peptide HRH was able to block
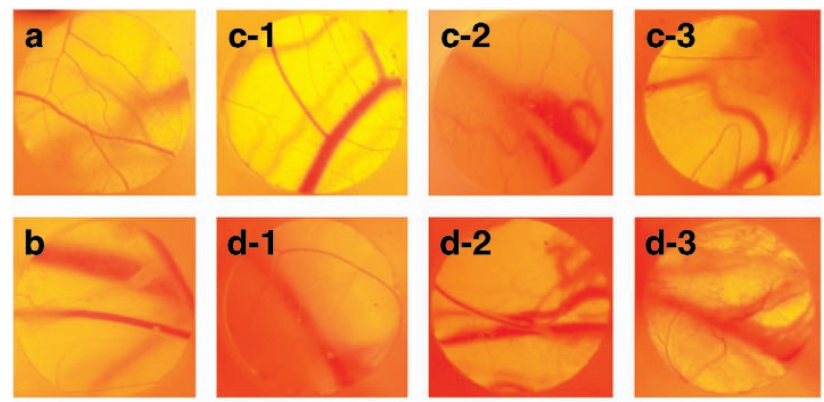

e

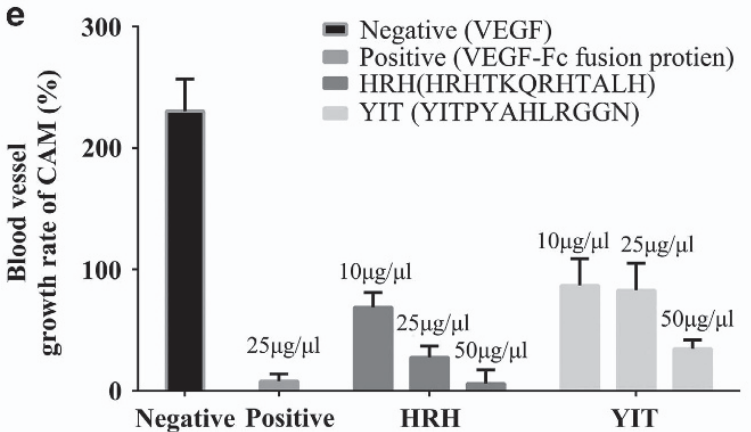

Figure 3. The effect of peptide HRH on inhibition of angiogenesis in chorioallantoic membrane. Capillaries were photographed: (a) PBS; (b) VEGFR-Fc fusion protein; (c-1) $10 \mu \mathrm{g} \mathrm{\mu l} \mathrm{l}^{-1}$ YIT; (c-2) $25 \mu \mathrm{g} \mathrm{\mu l} \mathrm{l}^{-1} \mathrm{YIT}$; (c-3) $50 \mu \mathrm{g} \mathrm{\mu l} \mathrm{I}^{-1} \mathrm{YIT}$; (d-1) $10 \mu \mathrm{g} \mathrm{\mu l} \mathrm{I}^{-1} \mathrm{HRH}$; (d-2) $25 \mu \mathrm{g} \mu \mathrm{I}^{-1} \mathrm{HRH}$; (d-3) $50 \mu \mathrm{gl}^{-1} \mathrm{HRH}$. (Magnification $\times 10$ ). (e) Blood vessel growth rate of CAM. 
a

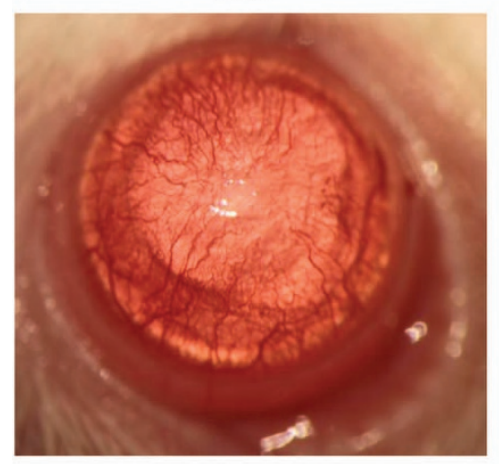

b

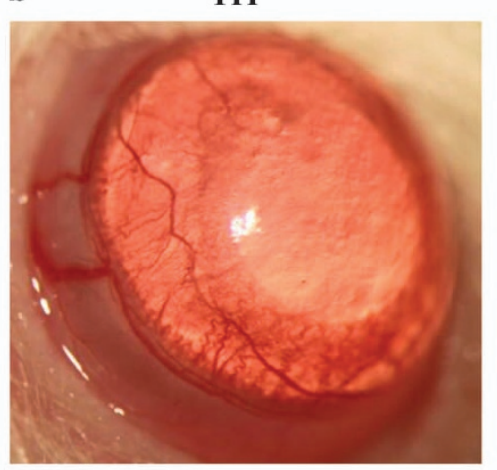

C

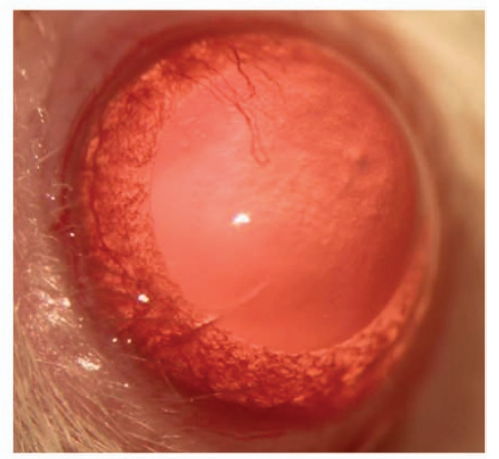

d

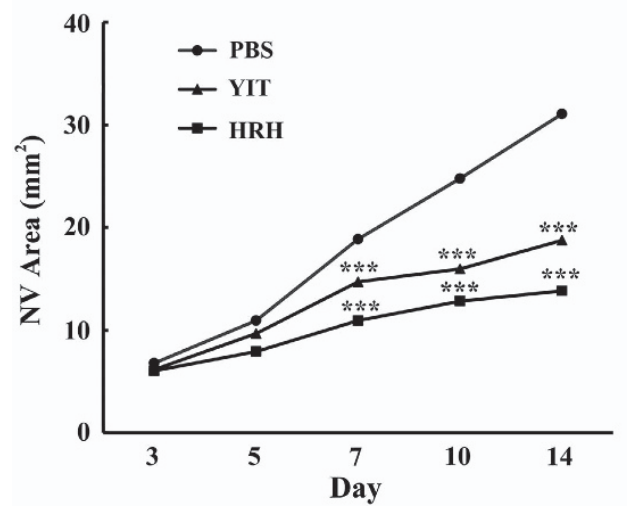

e

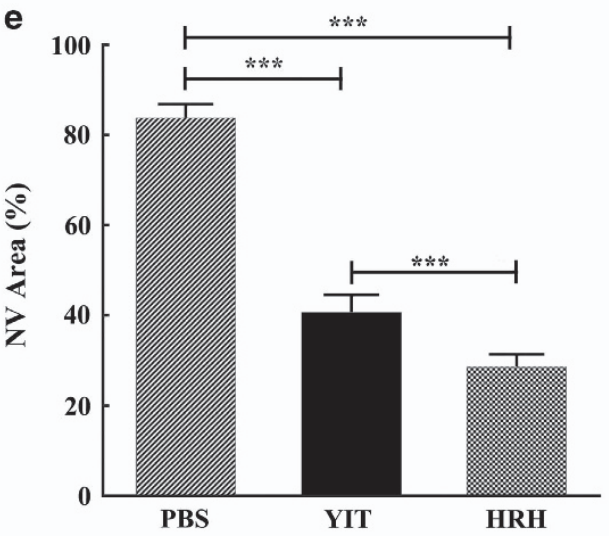

Figure 4. Effects of peptide HRH on corneal NV induced by alkali burn. The corneal NV was measured and photographed with a stereomicroscope after alkali burn. (a-c) Images of burned eyes treated with PBS, peptide YIT and peptide HRH at the concentration of $10 \mu \mathrm{gl}^{-1}$, respectively. (d, e) The total NV area was measured and analyzed. (data are presented as mean \pm s.e.m., $n=8$ in each group, $* * * P<0.001)$.

the generation of new blood vessels activated by VEGF in vitro. And the peptide could markedly reduce in vivo angiogenic activity dose-dependently in the CAM assay. In addition, the HRH peptide was also proved to inhibit corneal NV in an alkali-burnt rat corneal model and a suture-induced rat corneal model.

\section{Potential anti-angiogenesis mechanism of peptide $\mathrm{HRH}$}

The VEGF is a critical proangiogenic factor in NV, which acts through its receptors, VEGFR-1 and VEGFR- $2 .^{5}$ The VEGFR-Fc fusion proteins such as aflibercept ${ }^{27}$ and conbercept ${ }^{3}$ consist of the second Ig domain of VEGFR-1 and the third Ig domain of VEGFR-2. These fusion proteins have a broader affinity for VEGF molecules and have shown significant therapeutic effects on the treatment of AMD. ${ }^{3,44}$ In this study, we used VEGFR-Fc fusion protein as the target molecule and aimed to identify peptide ligands that can bind to VEGFR-1 and VEGFR-2. These peptides may have more advantages and better development prospects than those selected by natural VEGFR-1 or VEGFR-2. We found that the HRH peptide had the highest affinity to the VEGFR-Fc fusion protein. The epitope analysis results of the peptide were compared with genuine VEGFR-binding sites on ligands. As many as six residues in the epitope mapping result also appeared in the site that VEGF-B is bound to VEGFR-1. The significant overlapping suggests that the $\mathrm{HRH}$ peptide is a mimotope that mimicks the binding sites of VEGFR-1 on the VEGF-B. We found that three residues in the epitope mapping results also appeared in the interfaces of VEGFA/VEGFR-1 and VEGF-C/VEGFR-2 complexes, respectively (see the residues in bold in Table 2), whereas no residues overlapped with those of PIGF/VEGFR-1 and VEGF-A/VEGFR-2 complexes. On the basis of the above results, we infer that the HRH peptide can competitively inhibit the binding of VEGF-A and VEGF-B to VEGFR-1, and VEGF-C to VEGFR-2, leading to its antiangiogenesis activity. The exact biochemical mechanism of the $\mathrm{HRH}$ peptide and the effect of the peptide on VEGFRs intracellular pathways remain to be further studied.

Promising application prospects of anti-angiogenesis peptide $\mathrm{HRH}$ Anti-angiogenic agents are effective in the treatment of human cancers and fundus neovascular diseases. ${ }^{45}$ In combination with chemotherapy, they prolong the life of patients with certain types of cancers. ${ }^{46}$ Furthermore, anti-angiogenic treatments for ocular diseases characterized by growth of new blood vessel are commonly used, ${ }^{45}$ and have greatly reduced the incidence of blindness from exudative AMD. ${ }^{3}$ Since 2004, five angiogenesis inhibitors targeting VEGF have been introduced to ophthalmology, namely, pegaptanib, ranibizumab, bevacizumab, aflibercept and conbercept. ${ }^{3}$ These drugs produce promising therapeutic effects in patients with neovascular AMD. It has also been reported that anti-angiogenic therapy provides a possible therapeutic choice for the treatment of diet-induced obesity and metabolic complications. ${ }^{47-51}$ Given this, it is convinced that this novel angiogenic inhibitor will have wide application prospects.

\section{CONCLUSION}

In the present study, we successfully discovered a novel antiangiogenesis peptide from a random phage peptide library, which can significantly restrain the development of new blood vessels 
a

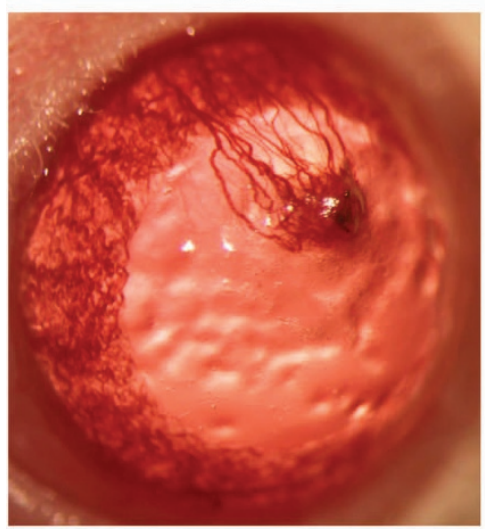

d

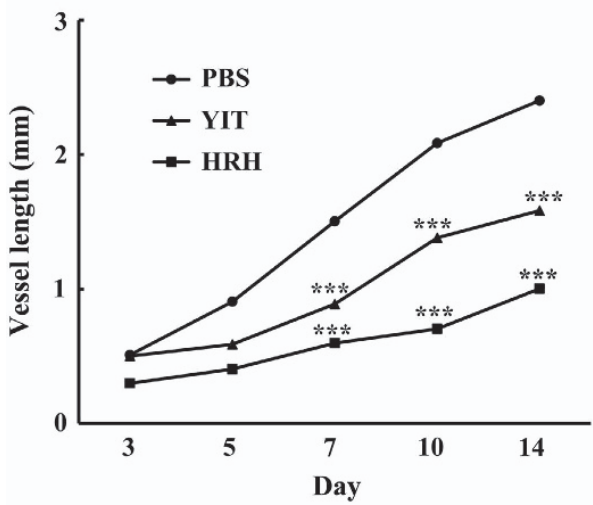

b

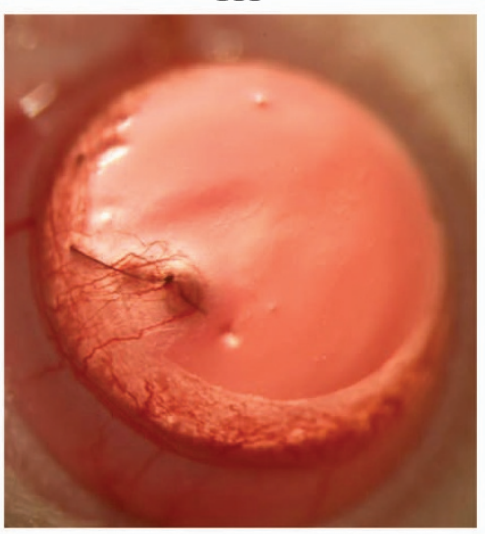

C

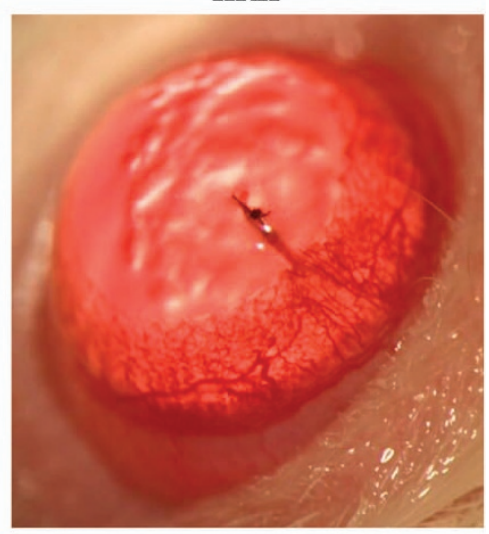

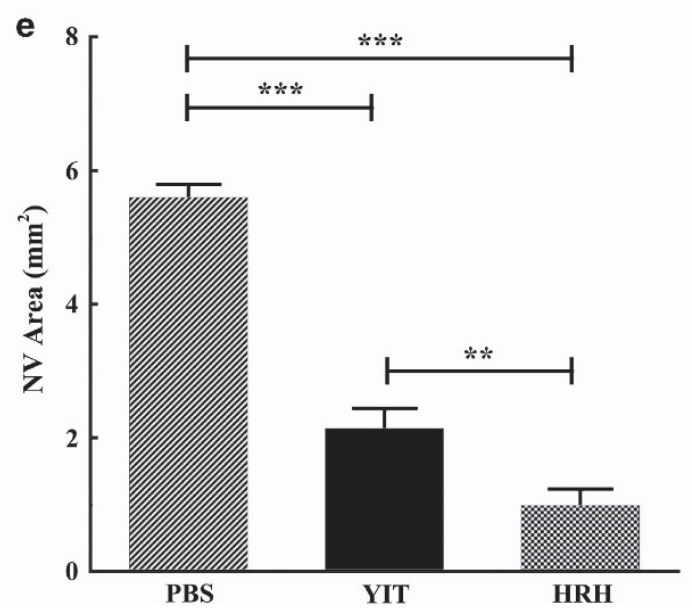

Figure 5. Effects of peptide HRH on NV induced by intrastromal suture. Corneal NV was measured and photographed with a stereomicroscope after intrastromal suture. (a-c) Images of group PBS, group peptide YIT, peptide HRH at the concentration of $10 \mu \mathrm{g} \mu \mathrm{I}^{-1}$. (d, e) The length of the longest vessel and the total corneal NV area were measured and analyzed. (data are presented as mean \pm s.e.m., $n=8$ in each group, $\left.* * * P<0.001,{ }^{* *} 0.001<P<0.003\right)$.

in vitro and in vivo, and inhibit corneal NV in an alkali-burnt rat corneal model and a suture-induced rat corneal model. The peptide provides a new candidate for suppressing the occurrence of new blood vessels. Peptide $\mathrm{HRH}$ holds great promise as a therapeutic lead agent for the treatment of complex angiogenesis-related pathological disorders.

\section{ACKNOWLEDGEMENTS}

The study is supported by National Natural Science Foundation of China (61571095), Program for New Century Excellent Talents in University (NCET-12-0088) and the Fundamental Research Funds for the Central Universities (ZYGX2015Z006).

\section{COMPETING INTEREST}

The authors declare no conflict of interests

\section{REFERENCES}

1 Bressler SB. Introduction: understanding the role of angiogenesis and antiangiogenic agents in age-related macular degeneration. Ophthalmology 2009; 116: S1-S7.

2 Carmeliet P. Angiogenesis in life, disease and medicine. Nature 2005; 438: 932-936.

3 Lu X, Sun X. Profile of conbercept in the treatment of neovascular age-related macular degeneration. Drug Des Devel Ther 2015; 9: 2311-2320.

4 Asano MK, Dray PB. Retinopathy of prematurity. Dis Mon 2014; 60: 282-291.
5 Holmes K, Roberts OL, Thomas AM, Cross MJ. Vascular endothelial growth factor receptor-2: structure, function, intracellular signalling and therapeutic inhibition. Cell Signal 2007; 19: 2003-2012.

6 Ferrara N, Adamis AP. Ten years of anti-vascular endothelial growth factor therapy. Nat Rev Drug Discov 2016; 15: 385-403.

7 Campa C, Harding SP. Anti-VEGF compounds in the treatment of neovascular age related macular degeneration. Curr Drug Targets 2011; 12: 173-181.

8 Kimoto K, Kubota T. Anti-VEGF agents for ocular angiogenesis and vascular permeability. J Ophthalmol 2012; 2012: 852183.

9 Ribatti D. Tumor refractoriness to anti-VEGF therapy. Oncotarget 2016; 7: 46668-46677.

10 Group CR, Martin DF, Maguire MG, Ying GS, Grunwald JE, Fine SL et al. Ranibizumab and bevacizumab for neovascular age-related macular degeneration. N Engl J Med 2011; 364: 1897-1908.

11 Heier JS, Boyer D, Nguyen QD, Marcus D, Roth DB, Yancopoulos G et al. The 1-year results of CLEAR-IT 2, a phase 2 study of vascular endothelial growth factor trapeye dosed as-needed after 12-week fixed dosing. Ophthalmology 2011; 118: 1098-1106.

12 Do DV, Schmidt-Erfurth U, Gonzalez VH, Gordon CM, Tolentino M, Berliner AJ et al. The DA VINCl study: phase 2 primary results of VEGF Trap-Eye in patients with diabetic macular edema. Ophthalmology 2011; 118: 1819-1826.

13 Zhang M, Zhang J, Yan M, Luo D, Zhu W, Kaiser PK et al. A phase 1 study of KH902, a vascular endothelial growth factor receptor decoy, for exudative age-related macular degeneration. Ophthalmology 2011; 118: 672-678.

14 Stewart MW. Aflibercept (VEGF Trap-Eye) for the treatment of exudative agerelated macular degeneration. Expert Rev Clin Pharmacol 2013; 6: 103-113.

15 Li X, Xu G, Wang Y, Xu X, Liu X, Tang S et al. Safety and efficacy of conbercept in neovascular age-related macular degeneration: results from a 12-month randomized phase 2 study: AURORA study. Ophthalmology 2014; 121: 1740-1747. 
16 Jaffe GJ, Martin DF, Toth CA, Daniel E, Maguire MG, Ying GS et al. Macular morphology and visual acuity in the comparison of age-related macular degeneration treatments trials. Ophthalmology 2013; 120: 1860-1870.

17 Craik DJ, Fairlie DP, Liras S, Price D. The future of peptide-based drugs. Chem Biol Drug Des 2013; 81: 136-147.

18 Sun Q, Xu X. A promising future for peptides in ophthalmology: work effectively and smartly. Curr Med Chem 2015; 22: 1030-1040.

19 Smith GP. Filamentous fusion phage: novel expression vectors that display cloned antigens on the virion surface. Science 1985; 228: 1315-1317.

20 Hamzeh-Mivehroud M, Alizadeh AA, Morris MB, Church WB, Dastmalchi S. Phage display as a technology delivering on the promise of peptide drug discovery. Drug Discov Today 2013; 18: 1144-1157.

21 Li T, Tu W, Liu Y, Zhou P, Cai K, Li Z et al. A potential therapeutic peptide-based neutralizer that potently inhibits Shiga toxin 2 in vitro and in vivo. Sci Rep 2016; 6: 21837.

22 Tiwari V, Liu J, Valyi-Nagy T, Shukla D. Anti-heparan sulfate peptides that block herpes simplex virus infection in vivo. J Biol Chem 2011; 286: 25406-25415.

23 Huang J, Derda R, Huang Y. Phage display informatics. Comput Math Methods Med 2013; 2013: 698395.

24 He B, Mao C, Ru B, Han H, Zhou P, Huang J. Epitope mapping of metuximab on CD147 using phage display and molecular docking. Comput Math Methods Med 2013; 2013: 983829.

25 Giordano RJ, Cardo-Vila M, Lahdenranta J, Pasqualini R, Arap W. Biopanning and rapid analysis of selective interactive ligands. Nat Med 2001; 7: 1249-1253.

26 Sidman RL, Li J, Lawrence M, Hu W, Musso GF, Giordano RJ et al. The peptidomimetic Vasotide targets two retinal VEGF receptors and reduces pathological angiogenesis in murine and nonhuman primate models of retinal disease. Sci Transl Med 2015; 7: 309ra165.

27 Holash J, Davis S, Papadopoulos N, Croll SD, Ho L, Russell M et al. VEGF-Trap: a VEGF blocker with potent antitumor effects. Proc Natl Acad Sci USA 2002; 99: $11393-11398$.

28 Xu Y, Zhao H, Zheng Y, Gu Q, Ma J, Xu X. A novel antiangiogenic peptide derived from hepatocyte growth factor inhibits neovascularization in vitro and in vivo. Mol Vis 2010; 16: 1982-1995.

29 Su L, Xu X, Zhao H, Gu Q, Zou H. In vitro and in vivo antiangiogenic activity of a novel deca-peptide derived from human tissue-type plasminogen activator kringle 2. Biochem Biophys Res Commun 2010; 396: 1012-1017.

30 Liu X, Lin Z, Zhou T, Zong R, He H, Liu Z et al. Anti-angiogenic and antiinflammatory effects of SERPINA3K on corneal injury. PLoS One 2011; 6: e16712.

31 Lu Y, Zheng Y, Ai J, Xu X. Therapeutic effects of a novel PIGF-1 derived peptide, ZY-1, on corneal neovascularization in vitro and in vivo. Discov Med 2016; 21: 349-361.

$32 \mathrm{Lu} \mathrm{Y,} \mathrm{Xu} \mathrm{Y,} \mathrm{Gu} \mathrm{Q,} \mathrm{Xu} \mathrm{X.} \mathrm{Inhibition} \mathrm{of} \mathrm{pathologic} \mathrm{corneal} \mathrm{neovascularization} \mathrm{by}$ topical application of a novel peptide in vivo. Cornea 2015; 34: 1295-1302.

33 Kenyon BM, Browne F, D'Amato RJ. Effects of thalidomide and related metabolites in a mouse corneal model of neovascularization. Exp Eye Res 1997; 64: 971-978.

34 He B, Chai G, Duan Y, Yan Z, Qiu L, Zhang H et al. BDB: biopanning data bank. Nucleic Acids Res 2016; 44: D1127-D1132.

35 Huang J, Ru B, Zhu P, Nie F, Yang J, Wang X et al. MimoDB 2.0: a mimotope database and beyond. Nucleic Acids Res 2012; 40: D271-D277.
36 Ru B, Huang J, Dai P, Li S, Xia Z, Ding H et al. MimoDB: a new repository for mimotope data derived from phage display technology. Molecules 2010; 15: 8279-8288.

37 Huang J, Ru B, Li S, Lin H, Guo FB. SAROTUP: scanner and reporter of targetunrelated peptides. J Biomed Biotechnol 2010; 2010: 101932.

38 He B, Kang J, Ru B, Ding H, Zhou P, Huang J. SABinder: a web service for predicting streptavidin-binding peptides. Biomed Res Int 2016; 2016: 9175143.

39 Huang J, Ru B, Dai P. Bioinformatics resources and tools for phage display. Molecules 2011; 16: 694-709.

40 Negi SS, Braun W. Automated detection of conformational epitopes using phage display Peptide sequences. Bioinform Biol Insights 2009; 3: 71-81.

41 Estephan E, Dao J, Saab MB, Panayotov I, Martin M, Larroque C et al. SVSVGMKPSPRP: a broad range adhesion peptide. Biomed Tech 2012; 57: 481-489.

42 Menendez A, Scott JK. The nature of target-unrelated peptides recovered in the screening of phage-displayed random peptide libraries with antibodies. Anal Biochem 2005; 336: 145-157.

43 Vodnik M, Zager U, Strukelj B, Lunder M. Phage display: selecting straws instead of a needle from a haystack. Molecules 2011; 16: 790-817.

44 Kaiser PK. Emerging therapies for neovascular age-related macular degeneration: drugs in the pipeline. Ophthalmology 2013; 120: S11-S15.

45 Cao Y, Arbiser J, D'Amato RJ, D'Amore PA, Ingber DE, Kerbel R et al. Forty-year journey of angiogenesis translational research. Sci Transl Med 2011; 3: $114 \mathrm{rv} 113$.

46 Cao Y. Antiangiogenic cancer therapy: why do mouse and human patients respond in a different way to the same drug? Int J Dev Biol 2011; 55: 557-562.

47 White HM, Acton AJ, Considine RV. The angiogenic inhibitor TNP-470 decreases caloric intake and weight gain in high-fat fed mice. Obesity 2012; 20: 2003-2009.

48 Woo S, Yoon M, Kim J, Hong Y, Kim MY, Shin SS et al. The anti-angiogenic herbal extract from Melissa officinalis inhibits adipogenesis in 3T3-L1 adipocytes and suppresses adipocyte hypertrophy in high fat diet-induced obese C57BL/6J mice. J Ethnopharmacol 2016; 178: 238-250.

49 Park BY, Lee H, Woo S, Yoon M, Kim J, Hong Y et al. Reduction of adipose tissue mass by the angiogenesis inhibitor ALS-L1023 from Melissa officinalis. PLOS ONE 2015; 10: e0141612.

50 Lee $\mathrm{H}$, Park D, Yoon M. Korean red ginseng (Panax ginseng) prevents obesity by inhibiting angiogenesis in high fat diet-induced obese C57BL/6J mice. Food Chem Toxicol 2013; 53: 402-408.

51 Cao Y. Adipose tissue angiogenesis as a therapeutic target for obesity and metabolic diseases. Nat Rev Drug Discov 2010; 9: 107-115.

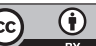

This work is licensed under a Creative Commons Attribution 4.0 International License. The images or other third party material in this article are included in the article's Creative Commons license, unless indicated otherwise in the credit line; if the material is not included under the Creative Commons license, users will need to obtain permission from the license holder to reproduce the material. To view a copy of this license, visit http://creativecommons.org/licenses/ by/4.0/

(c) The Author(s) 2017 